\title{
Unusual histology in primary pulmonary synovial sarcoma: Pearls to avoid misdiagnosis
}

\author{
Hartel PH ${ }^{1,2 *}$ and Parker $\mathrm{JE}^{2}$ \\ ${ }^{1}$ Departments of Histopathology, Sligo University Hospital, Sligo, Ireland \\ ${ }^{2}$ Department of Medicine, Section of Pulmonary and Critical Care Medicine, West Virginia University School of Medicine, Morgantown, WV, USA
}

\begin{abstract}
Primary pulmonary synovial sarcoma is rare and poses a diagnostic challenge when unusual histologic features are npresent and $t(x ; 18)$ is negative. Seventeen cases of primary pulmonary synovial sarcoma were evaluated to define unusual histologic features that may result in misdiagnosis. Clinically and radiologically these tumors showed identical characteristics of typical pulmonary synovial sarcomas, as they did histologically with dense cellularity, interlacing fascicles, hyalinized stroma, hemangiopericytoma-like vasculature, focal myxoid change, and entrapped benign pulmonary epithelium. They differed in that unusual histologic features not usually seen with pulmonary synovial sarcoma but typical of other neoplasms were focally present. These included Verocay bodies, rosettes, papillary structures with fibrovascular cores, adenomatoid change, and rhabdoid morphology. Immunohistochemistry demonstrated typical expression of focal cytokeratins, vimentin, and occasional CD99, Bcl-2, and smooth muscle actin. These tumours were often negative or showed weak amplification for $\mathrm{t}(\mathrm{x} ; 18)$. In conclusion, awareness of focal unusual histology in otherwise typical pulmonary synovial sarcoma can prevent misdiagnosis, particularly when $t(x ; 18)$ is negative.
\end{abstract}

\section{Introduction}

Primary pulmonary synovial sarcoma is an aggressive tumor sharing common histologic features with soft tissue synovial sarcoma [1-5]. Molecular testing for the pathognomonic $t(x ; 18)$ chromosomal translocation has enabled diagnostic confirmation in approximately $90 \%$ of cases [6]. In $t(x ; 18)$ negative cases, diagnosis must rely on histologic and immunophenotypic features. The differential diagnosis of primary pulmonary synovial sarcoma is particularly challenging when histologic features unusual to synovial sarcoma, but common to other neoplasms are focally present. This challenge is compounded with negative $t(x ; 18)$ findings. We evaluated 17 cases of primary pulmonary synovial sarcoma where unusual histology was present to bring awareness of atypical morphology in this entity.

\section{Materials and Methods}

Sixty cases of known pulmonary synovial sarcoma from 1981 to 2006 were retrieved from tissue archives. Seventeen cases that contained focal unusual histologic features were included. Computed tomography, magnetic resonance imaging, or positron emission tomography/computed tomography studies were available in 4 cases. Follow-up data were obtained from patient records. Hematoxylin and eosin stained sections were available for each case. Tumors were subtyped as monophasic or biphasic according to World Health Organization criteria [7]. Grading by tumor cell differentiation, mitotic rate, and necrosis was performed following the French Federation of Cancer Centers (FNCLCC) scheme. Unusual histologic features were noted and immunohistochemistry was performed on paraffin embedded sections using commercially available antibodies (Table 1). Molecular analysis was performed on RNA extracted from paraffin embedded samples. SYT/SSX RNA fusion transcripts resulting from $\mathrm{t}(\mathrm{x} ; 18)(\mathrm{p} 11 ; \mathrm{q} 11)$ translocation were detected using real-time reverse transcriptase-polymerase chain reaction.(8) Subtyping of SYT/SSX 1 and 2 fusion transcripts was performed using methods previously described [8].

\section{Results}

\section{Clinical findings}

Pertinent clinical features are presented in Table 2. The study group included 6 males and 11 females ranging from 10 to 76 years of age (mean, 45). The most common presenting symptoms were dyspnea and shortness of breath. Tumors were distributed in the lung [8], pleura [8], and mediastinum [1]. Surgical procedures of primary tumour included lobectomy [4], excision [8], and biopsy [5]. Local recurrence, metastases, and survival data did not differ from typical pulmonary synovial sarcoma (Hartel et al). Radiology included 2 computed tomography studies, 1 magnetic resonance imaging study, and 1 case with fluorine-18-fluorodeoxyglucose positron emission tomography/computed tomography images. Findings were similar to typical pulmonary synovial sarcoma as previously reported Figure 1 [9].

\section{Gross and histologic findings}

Gross and histologic findings are presented in Table 3. Tumors ranged in size from 0.6 to16 centimeters (mean, 7.5) and were wellcircumscribed, soft, tan masses with foci of necrosis, hemorrhage, and cystic change. Histologically, tumors were monophasic [10] or biphasic [4]. Tumors were grade 2 [11] and grade 3 (poorly differentiated, 6) according to French Federation of Cancer Centers (FNCLCC) grading. Among poorly differentiated tumors, 16 were monophasic and 1 was biphasic. Tumor cell morphology included spindle cells or a combination of spindle and round/epithelioid cells. Mitoses ranged

*Correspondence to: Hartel PH, Histology, Level 4, Sligo University Hospital, The Mall Sligo, Co. Sligo, Ireland, E-mail: hartelp@davishealthsystem.org

Key words: pulmonary, pleura, synovial sarcoma

Received: May 07 2018; Accepted: May 23, 2018; Published: May 25, 2018 


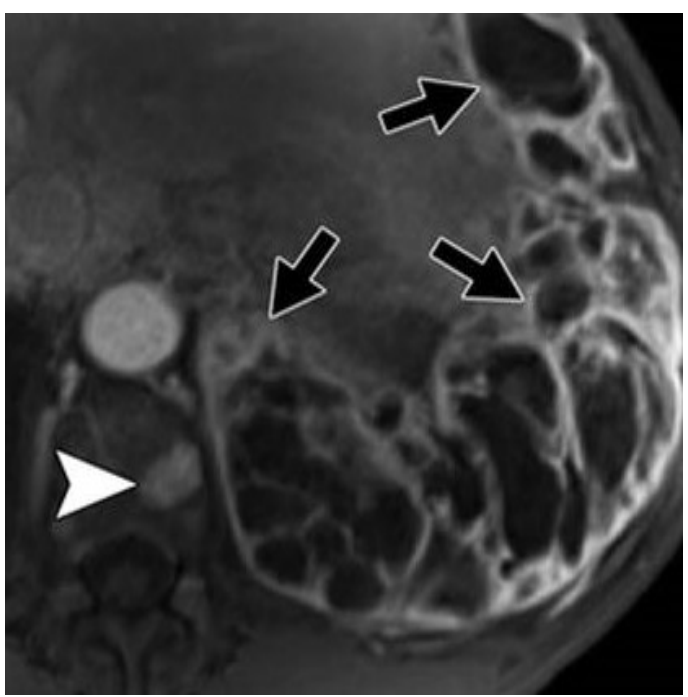

Figure 1. Synovial sarcoma in a 36 year-old male with dyspnea and pleuritic chest pain. Axial T2-weighted (2110/57.6) Magnetic resonance image shows greater contrast amongst internal components, with well demarcated spaces (arrowheads) which suggest cysts.

from 3 to 95 per 10 high power fields (mean, 18). Necrosis was present in 13 tumors and rarely extensive [1].

Histologic features typical of pulmonary synovial sarcoma were seen and included dense cellularity, interlacing fascicles, and hyalinized or eosinophilic stroma. Hemangiopericytoma-like vasculature (15), focal myxoid change [11] and benign entrapped pneumocytes [12] were also seen. Unusual histologic features were focal, noted in at least 1 but no more than 4 slides per case, varying from 4 to 90 high power fields and included Verocay body-like areas [7], vague rosette formation [6], well-formed papillary structures [3], adenomatoid areas [3], and rhabdoid morphology (Figure 2) [2].

\section{Immunohistochemical and molecular findings}

Immunohistochemical findings are presented in Table 4 and molecular findings in Table 5. Immunohistochemical studies showed focal positive membranous or cytoplasmic staining for epithelial markers including pancytokeratin (14), epithelial membrane antigen [8], and cytokeratin 7 [7], while three cases showed focal immunoreactivity for all 3 epithelial markers. One tumor was also focally positive for cytokeratin 5/6. Diffuse immunoreactivity was seen with Bcl-2 in four cases and CD99 in seven cases. Focal immunoreactivity was present with CD56 [5], S-100 [4], calretinin [3], and smooth muscle actin [2]. Entrapped benign pneumocytes, present in seven cases, were immunoreactive with thyroid transcription factor-1 and epithelial markers.

The chromosomal translocation $\mathrm{t}(\mathrm{x} ; 18)$ was present in 9 cases studied in which 3 were fusion type SYT/SSX1 and 5 fusion type SYT/ SSX2. One case was reported as $\mathrm{t}(\mathrm{x} ; 18)$ positive without information on the SSX fusion type.

\section{Discussion}

Synovial sarcoma, although rare, is a primary pulmonary neoplasm with distinctive histology. The presence of focal unusual histologic findings characteristic of more common epithelial and mesenchymal tumors may lead to misdiagnosis. This is particularly problematic in small biopsies or in primary pulmonary synovial sarcomas that are negative for the pathognomonic $\mathrm{t}(\mathrm{x} ; 18)$ translocation. We present 17 primary pulmonary synovial sarcoma cases with unusual histologic features.
Table 1. Antibodies

\begin{tabular}{|l|l|l|l|}
\hline & Clone & Titer & Source \\
\hline Pancytokeratin & AE1/AE3 & $1: 200$ & $\begin{array}{l}\text { Roche, Mannheim, } \\
\text { Germany }\end{array}$ \\
\hline Cytokeratin-7 & OV TL12/30 & $1: 160$ & Dako, Carpinteria, CA \\
\hline Epithelial membrane antigen & E29 & $1: 100$ & Dako, Carpinteria, CA \\
\hline Thyroid Transcription Factor-1 & $8 \mathrm{G} 7 \mathrm{G} 3 / 1$ & $1: 25$ & Dako, Carpinteria, CA \\
\hline Cytokeratin 5/6 & D5/16B4 & $1: 20$ & Dako, Carpinteria, CA \\
\hline Calretinin & CAL 3F5 & $1: 50$ & Zymed, San Francisco, CA \\
\hline Bcl-2 & 124 & $1: 20$ & Dako, Carpinteria, CA \\
\hline CD56 & $123 \mathrm{C} 3$ & $1: 100$ & Caltag, Burlingame, CA \\
\hline CD99 & 12E7 & $1: 80$ & Dako, Carpinteria, CA \\
\hline S-100 & Polyclonal & $1: 800$ & Dako, Carpinteria, CA \\
\hline Smooth Muscle Actin & 1A4 & $1: 800$ & Sigma, St. Louis, MO \\
\hline & & & \\
\hline
\end{tabular}

Table 2. Clinical findings

\begin{tabular}{|l|l|}
\hline Mean age, years & $\mathbf{4 5}$ \\
\hline Gender: & 6 \\
\hline Male & 11 \\
\hline Female & \\
\hline Common symptoms: & 5 \\
Dyspnea & 5 \\
Chest pain & 4 \\
Cough & 3 \\
\hline Pleural effusion & \\
\hline Tumor location: & 8 \\
Lung & 8 \\
Pleura & 1 \\
\hline Mediastinum & \\
\hline Treatment: & 4 \\
Lobectomy & 8 \\
Excision of mass & 5 \\
Open biopsy & \\
\hline
\end{tabular}

Table 3. Gross and histologic findings

\begin{tabular}{|l|r|}
\hline Mean tumor size, cm & 7.5 \\
\hline Subtypes & 13 \\
Monophasic & 4 \\
Biphasic & \\
\hline Unusual (common to other neoplasms, & \\
focally present) & 7 \\
$\quad$ Verocay body-like areas & 6 \\
Vague rosette formation & 3 \\
Papillary structures & 3 \\
Adenomatoid areas & 2 \\
Rhabdoid morphology & \\
\hline
\end{tabular}

Table 4. Immunohistochemical findings

\begin{tabular}{|l|c|}
\hline Pancytokeratin & 14 \\
\hline Epithelial Membrane Antigen & 8 \\
\hline Cytokeratin -7 & 7 \\
\hline Calretinin & 3 \\
\hline Cytokeratin 5/6 & 1 \\
\hline CD99 & 7 \\
\hline Bcl-2 & 4 \\
\hline CD56 & 5 \\
\hline S-100 & 4 \\
\hline Smooth Muscle Actin & 2 \\
\hline
\end{tabular}

Table 5. Molecular findings

Total $t(x ; 18)$ positive

Total SYT/SSX1

Total SYT/SSX2

Total $t(x ; 18)$ positive, SSX unknown

Total $t(x ; 18)$ negative 

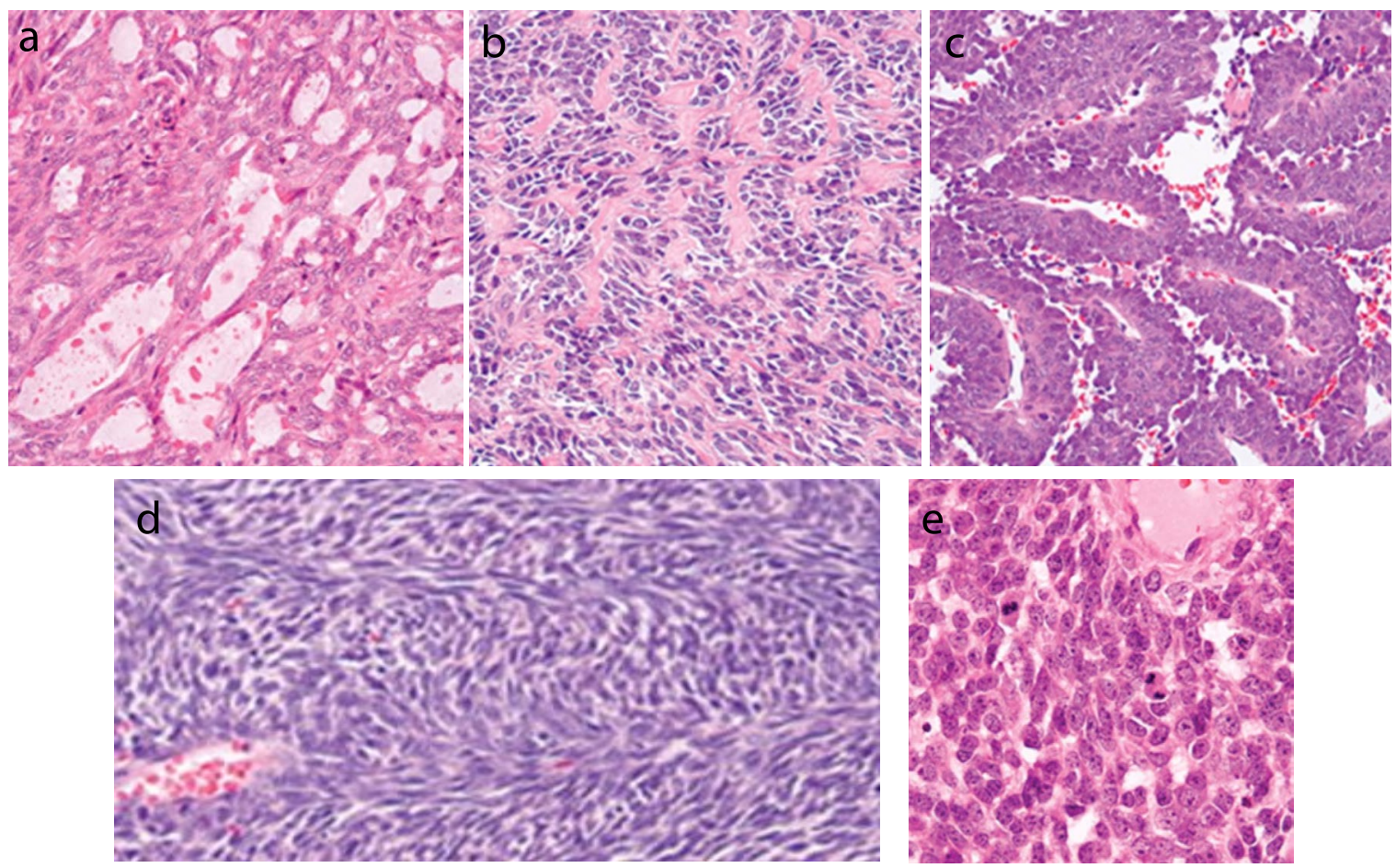

Figure 2. Typical histologic features of pulmonary synovial sarcoma characteristically composed of densely cellular interlacing fascicles (a). Unusual features that may lead to misdiagnosis include papillary formations (b), Verocay body-like areas (c), adenomatoid appearance (d), and rhabdoid morphology (e) or vague rosette formation.

The focal unusual histology in primary pulmonary synovial sarcoma can erroneously suggest more common primary and metastatic pulmonary neoplasms. Verocay body-like areas can occur [1] which are similar to those seen in malignant peripheral nerve sheath tumor [12]. The stromal background of malignant peripheral nerve sheath tumor, however, typically lacks hyalinization and appears more basophilic. While focal immunoreactivity for S-100 can be present in both tumors [12], primary pulmonary synovial sarcoma is often immunoreactive for cytokeratin 7 , a finding not generally seen in malignant peripheral nerve sheath tumor [11]. Clinically, malignant peripheral nerve sheath tumors arise from nerve or neurofibroma and are associated with neurofibromatosis type I in approximately twothirds of cases [12].

Primary pulmonary synovial sarcoma with focal vague rosette formation can lead to misdiagnosis as primitive neuroectodermal tumor $[6,12]$. Primary pulmonary synovial sarcoma may also be reminiscent of primitive neuroectodermal tumor when the former is poorly differentiated and displays round cell morphology. Unlike primary pulmonary synovial sarcoma, primitive neuroectodermal tumor typically has distinct cell borders, clear cytoplasm, scant stroma, and lacks hemangiopericytoma-like vasculature. Both tumors can express CD99, CD56, and cytokeratins [12,10], although expression of cytokeratin 7 makes a diagnosis of primitive neuroectodermal tumor less likely [13]. Chromosomal translocation $\mathrm{t}(11 ; 22)$ is present in $85 \%$ of primitive neuroectodermal tumors [6].

Focal well-formed papillary [5] or adenomatoid areas in primary pulmonary synovial sarcoma may be misinterpreted as carcinoma or malignant mesothelioma. In particular, pleomorphic carcinoma can present with spindle cell and adenocarcinoma components. Carcinomas are more cytologically atypical with greater pleomorphism than primary pulmonary synovial sarcoma. Carcinomas may have areas of squamous differentiation or contain tumor giant cells, features not observed in primary pulmonary synovial sarcoma. While cytokeratins are focally expressed in primary pulmonary synovial sarcoma, diffuse positivity for epithelial markers is not characteristic. However, it should be kept in mind that spindle cell carcinomas may also be only focally positive for cytokeratins. Carcinomas are more likely to show an infiltrative growth pattern, regional lymph node involvement, and/ or widespread metastases. While pulmonary synovial sarcomas may express calretinin and CK5/6, radiologically they are dissimilar to mesothelioma presenting with a pulmonary parenchymal mass rather than diffuse pleural involvement.

We present 17 primary pulmonary synovial sarcoma cases with focal unusual histologic features that may erroneously suggest more common primary and metastatic pulmonary neoplasms. This unusual histology may be particularly challenging in small biopsies or when $\mathrm{t}(\mathrm{x} ; 18)$ is negative. In contrast to usual pulmonary synovial sarcoma, $t(x ; 18)$ was negative in nearly half of the cases presented here, higher than the expected $10 \%$. Awareness of typical histology of pulmonary synovial sarcoma, their potential misleading unusual morphologic features, and prudent use of immunohistochemistry will prevent misdiagnosis, even in $\mathrm{t}(\mathrm{x} ; 18)$-negative cases.

\section{Conflict of interest}

None of the authors have any disclosures or conflicts of interest.

\section{References}

1. Zeren H, Moran CA, Suster S, Fishback NF, Koss MN (1995) Primary pulmonary sarcomas with features of monophasic synovial sarcoma: a clinicopathological, immunohistochemical, and ultrastructural study of 25 cases. Hum Pathol 26: 474-480. [Crossref]

2. Begueret H, Galateau-Salle F, Guillou L, Chetaille B, Brambilla E, et al. (2005) Primary intrathoracic synovial sarcoma: a clinicopathologic study of $40 \mathrm{t}(\mathrm{x} ; 18)$-positive cases from the French Sarcoma Group and the Mesopath Group. Am J Surg Pathol 29: 339346. [Crossref] 
3. Essary LR, Vargas SO, Fletcher CD (2002) Primary pleuropulmonary synovial sarcoma: reappraisal of a recently described anatomic subset. Cancer 94: 459-469. [Crossref]

4. Okamoto S, Hisaoka M, Daa T, Hatakeyama K, Iwamasa T, et al. (2004) Primary pulmonary synovial sarcoma: a clinicopathologic, immunohistochemical, and molecular study of 11 cases. Hum Pathol 35: 850-856. [Crossref]

5. Suster S, Moran CA (2005) Primary synovial sarcomas of the mediastinum: a clinicopathologic, immunohistochemical, and ultrastructural study of 15 cases. Am J Surg Pathol 29: 569-578. [Crossref]

6. Fletcher CD, Unni KK, Mertens FE (2002) World Health Organization Classification of Tumors. Pathology and Genetics of Tumors of Soft Tissue and Bone. IARC Press: Lyon, France pp. 427.

7. Travis WD, Brambilla E, Muller-Hermelink HK, Harris CC (2004) World Health Organization Classification of Tumors. Pathology and Genetics of Tumors of the Lung, Pleura, Thymus, and Heart. IARC Press: Lyon, France pp. 344.
8. Bijwaard KE, Fetsch JF, Przygodzki R, Taubenberger JK, Lichy JH (2002) Detection of SYT-SSX fusion transcripts in archival synovial sarcomas by real-time reverse transcriptase-polymerase chain reaction. J Mol Diagn 4: 59-64. [Crossref]

9. Hartel PH, Fanburg-Smith JC, Frazier AA, Galvin JR, Lichy JH, et al. (2007) Primary pulmonary and mediastinal synovial sarcoma: a clinicopathologic study of 60 cases and comparison with five prior series. Mod Pathol 20: 760-769. [Crossref]

10. Machen SK, Fisher C, Gautam RS, Tubbs RR, Goldblum JR (1998) Utility of cytokeratin subsets for distinguishing poorly differentiated synovial sarcoma from peripheral primitive neuroectodermal tumour. Histopathology 33: 501-507. [Crossref]

11. Smith TA, Machen SK, Fisher C, Goldblum JR (1999) Usefulness of cytokeratin subsets for distinguishing monophasic synovial sarcoma from malignant peripheral nerve sheath tumor. Am J Clin Pathol 112: 641-648. [Crossref]

12. Miettinen ME (2003) Diagnostic Soft Tissue Pathology. Churchill Livingstone: New York pp. 463-468.

13. Kleihues P, Cavenee WKE (2000) World Health Organization Classification of Tumors Pathology and Genetics of Tumors of the Central Nervous System pp.172-174.

Copyright: $\odot 2018$ Hartel PH. This is an open-access article distributed under the terms of the Creative Commons Attribution License, which permits unrestricted use, distribution, and reproduction in any medium, provided the original author and source are credited. 